\title{
Buen vivir y solidaridad económica en Villa del Carbón, México: racionalidades en disputa
}

Dania López-Córdova*

Maestra en Estudios Latinoamericanos, Universidad Autónoma de México, México.

Correo electrónico:

dania.lopez.cordova@gmail.com

Recibido: 17 de enero del 2016 Aceptado: 31 de mayo del 2016

Cómo citar este artículo: López-Córdova, D. (2016). Buen vivir y solidaridad económica en Villa del Carbón, México: racionalidades en disputa. Cooperativismo \& Desarrollo, 24(109), XX-Xx. doi: 10.16925/co.v24i109.1502

\section{Resumen}

Propósito: este artículo tiene como finalidad presentar algunas reflexiones sobre la solidaridad económica y el buen vivir a partir de los hallazgos encontrados en un pequeño municipio cercano a la capital del país. Descripción: Villa del Carbón es un municipio predominantemente rural, pero, por su ubicación, ocupa un lugar de interface - es un puente entre dos importantes regiones del país- donde se articulan diversos tiempos y espacios, con una complejidad que ilustra tensiones entre racionalidades: por un lado, los procesos de metropolización y desarrollo con su racionalidad instrumental, y, por el otro, la permanencia y actualización de los modos de vida basados en racionalidades reproductivas, solidarias y liberadoras. Punto de vista: se sostiene que existen experiencias de solidaridad económica —organizaciones productivas forestales, apícolas, agroecológicas, ecoturísticas-; sin embargo, estas se encuentran amenazadas y tensionadas de manera permanente por las exigencias del "desarrollo" y el capitalismo. Conclusiones: los rasgos de las prácticas de solidaridad económica, que encarnan racionalidades alternativas, racionalidades otras, deberían ser considerados para diseñar y aplicar políticas públicas de promoción y fortalecimiento.

Palabras clave: agroecología, buen vivir, desarrollo, racionalidades, reciprocidad, solidaridad económica. 


\title{
Good living and economic solidarity in Villa del Carbón, Mexico: competing rationales
}

\begin{abstract}
Purpose: This article seeks to present reflections on economic solidarity and good living based on findings in a small town near the country's capital. Description: Villa del Carbón is a predominantly rural town, but, due to its location, it is a point of interconnection-a bridge between two important regions of the country-where the town brings together diverse times and spaces through a complexity that illustrates tensions between rationales. These rationales are, on the one hand, the processes of metropolization and development with their instrumental rationality and, on the other, the permanence and revision of ways of life based on reproductive, solidarity, and liberating rationales. Viewpoint: It is argued that there are examples of economic solidarity such as forestry, apiculture, agroecological, and ecotourism productive organizations. However, these are constantly threatened and strained by the demands of development and capitalism. Conclusions: The features of economic solidarity practices-which make tangible alternative rationales, other rationales-should be considered to design and implement public policies of promotion and strengthening.
\end{abstract}

Keywords: agroecology, good living, development, rationales, reciprocity, economic solidarity.

\section{Bom viver e solidariedade econômica na Villa del Carbón, México: racionalidades em disputa}

\section{Resumo}

Propósito: este artigo tem como finalidade apresentar algumas reflexões sobre a solidariedade econômica e o bom viver a partir das descobertas encontradas num pequeno município próximo à capital do país. Descrição: Villa del Carbón é um município predominantemente rural, mas, por sua localização, ocupa um lugar de interface -é uma ponte entre duas importantes regiões do país- onde se articulam diversos tempos e espaços, com uma complexidade que ilustra tensões entre racionalidades: por um lado, os processos de metropolização e desenvolvimento com sua racionalidade instrumental, e, por outro, a permanência e atualização dos modos de vida baseados em racionalidades reprodutivas, solidárias e liberadoras. Ponto de vista: afirma-se que existem experiências de solidariedade econômica —organizações produtivas florestais, apícolas, agroecológicas, ecoturísticas-; no entanto, estas se encontram ameaçadas e tensionadas de maneira permanente pelas exigências do desenvolvimento e do capitalismo. Conclusões: as características das práticas de solidariedade econômica, que incorporam racionalidades alternativas, outras racionalidades, deveriam ser consideradas para desenvolver e aplicar políticas públicas de promoção e de fortalecimento.

Palavras-chave: agroecologia, bom viver, desenvolvimento, racionalidades, reciprocidade, solidariedade econômica. 


\section{Introducción ${ }^{1}$}

El buen vivir y la solidaridad económica son elementos que van cobrando gran relevancia en las últimas décadas, dada la crisis de la sociedad actual. Estos elementos se perfilan como prácticas y propuestas sociales alternativas al patrón de poder moderno/ colonial capitalista ${ }^{2}$ y al imaginario del desarrollo, pues desde la propuesta del buen vivir se apela por una vida en la cual predominen la relacionalidad, la reciprocidad y la complementariedad entre las personas y la naturaleza, esto es, por racionalidades liberadoras y solidarias (López y Marañón, 2013; Marañón y López, 2014). Por lo tanto, se rechazan las relaciones de dominación y explotación de dicho patrón: las personas ya no son clasificadas e inferiorizadas por supuestas diferencias raciales, y la naturaleza deja de tener el estatus de objeto, de "recurso" susceptible de ser usado para la insaciable valorización del capital, sin considerar las consecuencias negativas que dicho proceso acarrea para la vida misma. El buen vivir incluye además la novedad de originarse en la periferia de la periferia (no solo en la periferia como en el caso de la teoría de la dependencia): en los pueblos originarios de los países andinos (Tortosa, 2010). Por su parte, la solidaridad económica apunta al reconocimiento de prácticas económicas que se rigen por una racionalidad reproductiva y formas de trabajo colectivo no mercantil, que se alejan de la visión hegemónica de la economía, definida por la pervivencia tanto de individuos como de empresas orientados por el cálculo y la obtención de la utilidad máxima, y trabajadores que venden su fuerza de trabajo a cambio

Este artículo se enmarca en la investigación del proyecto DGAPA-PAPIIT IN303216, UNAM, "De la crisis estructural del empleo al trabajo recíproco en el México actual. Discursos y prácticas en organizaciones económicas solidarias".

2 La colonialidad del poder ( $\mathrm{CP})$ es una perspectiva teórica desarrollada por Aníbal Quijano, la cual plantea que el poder es constitutivo de la existencia social, entendido este como una relación de dominación, explotación y conflicto; este último alude a la disputa permanente por el control de los ámbitos básicos de existencia social: trabajo, autoridad colectiva, intersubjetividad, género y naturaleza. Quijano señala que desde la conquista de América, se estableció el primer patrón de poder mundial, caracterizado por ser moderno/colonial y capitalista. Mundial porque abarcó a toda la población; moderno porque se impuso el proyecto de la modernidad europea y la razón instrumental orientado a la acumulación capitalista, y colonial porque se legitimaron relaciones de dominación y explotación a partir de supuestas diferencias raciales. Para conocer la obra del autor, veáse Quijano (2014). de un salario cada vez más precario y sin condiciones de trabajo estables.

Estas propuestas y prácticas entran en disputa con aquellas que se han establecido desde el imaginario del capitalismo y su propuesta del desarrollo como hegemónicas, pues son minimizadas o invisibilizadas por estas últimas. Además, en no pocas situaciones son despojadas de su contenido emancipador al apropiarse discursivamente de éstas para ocultar relaciones de dominación y explotación. En el contexto actual son proyectos y experiencias que coexisten con la visión y práctica hegemónica de la economía y el cambio social, estableciendo complementariedades, pero sobre todo tensiones. Se trata de racionalidades en disputa.

En ese sentido, el propósito de esta contribución es mostrar la forma en que se establece esa disputa de racionalidades, a partir de las dinámicas encontradas en un pequeño municipio, Villa del Carbón, muy cercano a la Ciudad de México, D. C. La investigación se realizó a partir de una revisión documental pero principalmente de un conjunto de un conjunto de entrevistas abiertas realizadas entre septiembre y noviembre del 2014. A todas las personas que compartieron su palabra, nuestro agradecimiento. Asimismo, gracias a Guillermina y Gregorio por las transcripciones.

La estructura del trabajo es la siguiente: en el primer apartado, se discuten algunas cuestiones teóricas que ayudan a abordar el estudio de caso; en el segundo, se realiza una caracterización general de Villa del Carbón; en el tercero, se muestran los hallazgos encontrados a la luz de las reflexiones del primer apartado, y finalmente se presentan algunas conclusiones.

\section{Buen vivir, solidaridad económica y racionalidad}

Como ya ha sido señalado, el buen vivir alude a prácticas en las cuales la idea básica es restablecer las relaciones tanto de reciprocidad como de complementariedad entre las personas y la naturaleza. Surge principalmente de aportes de los pueblos indígenas, pero no se trata de una arqueología: es una respuesta a los problemas del desarrollo actual, y es una exploración de alternativas en el futuro (Gudynas, 2014); en ese sentido, confronta a la idea de desarrollo capitalista, que privilegia el crecimiento económico, la explotación de la naturaleza y la lógica del mercado.

Para Escobar (2009), el concepto desarrollo alude a un proyecto no solo económico, sino también 
cultural, originado de la experiencia europea que subordina culturas y conocimientos otros, a los que busca transformar ("modernizar") bajo principios occidentales, para salir de la "tradición" y del "subdesarrollo". Es tributaria del eurocentrismo la perspectiva de conocimiento hegemónica caracterizada por el dualismo/evolucionismo y una supuesta universalidad: el cambio social es entendido como una trayectoria ascendente unilineal — pasar del subdesarrollo al desarrollo, según los estándares europeos-; a partir de la dicotomía entre sujeto y objeto se instituyó la primacía de lo humano sobre lo no humano - separación entre cultura y naturaleza- y de ciertos humanos sobre otros - separación colonial entre "nosotros" y "los otros"- (Escobar, 2014).

En el buen vivir, los seres (humanos o no humanos) existen siempre en relación, nunca como objetos o individuos. No se concibe sin la comunidad ampliada a lo no humano, y se insiste en que todo está conectado, relacionado, bien sea en una complementariedad, bien en una reciprocidad; la primera nos habla de una necesidad mutua, en tanto que la segunda alude a una forma de reconocimiento del otro y de pertenencia a una colectividad humana, a una dinámica de don y redistribución creadora de lazo social, en la cual se producen y reproducen valores (amistad, confianza). Esto implica la integralidad entre lo humano y la naturaleza como un todo, y exige un dar y recibir entre todos los seres existentes (López, 2016).

Por su parte, la solidaridad económica ${ }^{3}$ alude a un conjunto heterogéneo de iniciativas colectivas desplegadas por trabajadores marginalizados para resolver sus necesidades materiales y subjetivas fundamentales, ante los cambios registrados en el mundo del trabajo asalariado, en particular, y del patrón de acumulación, en general.

En estas experiencias se van tejiendo relaciones de reciprocidad como relaciones sociales básicas y como una forma de organización y de gestión del trabajo - cooperación y trabajo colectivo-; también se caracterizan por hacer una distribución equitativa

\footnotetext{
$3 \quad$ No se utiliza el término de economía social y solidaria para tomar distancia de la epistemología de las ciencias liberales que compartimentalizan la realidad social en esferas diferenciadas y no relacionadas entre sí. Asimismo, ciertos promotores, activistas y académicos piensan que el cambio social está anclado en lo económico, de modo que la instalación de lo solidario en la economía sería suficiente para un cambio en la sociedad, lo que es problemático ya que el patrón de poder se asienta en otros ámbitos, no solo el económico.
}

de los excedentes cuando los hay y por una toma democrática de decisiones. Se trata de cooperativas, empresas comunales, sociedades de producción rural, colectivos, grupos de mujeres o jóvenes, experiencias de comercio justo, monedas comunitarias complementarias, finanzas solidarias, comedores comunitarios, etc.: todas estas, expresiones de una racionalidad reproductiva, esto es, una que prioriza la resolución de las necesidades y el bienestar tanto familiar como colectivo, por encima del lucro individual, una racionalidad en la cual "la vida se convierte en el criterio esencial de referencia" (Hinkelammert y Mora, 2005). En ese sentido, son portadoras de diversas especificidades que las alejan de la empresa tradicional, de la microempresa o de la economía informal. Si bien estas buscan satisfacer las necesidades más sentidas, pueden perfilarse como experiencias y propuestas orientadas hacia el buen vivir, pues se trata de prácticas económicas que, si se reconocen en su especificidad, cuestionan los conceptos dominantes de economía, riqueza, pobreza, trabajo, necesidad, eficiencia, propiedad, naturaleza, etc.; a su vez, impulsan procesos de desmercantilización (Marañón, 2012)

Desde la economía hegemónica se impuso una idea excluyente de economía que gira en torno al homo œeconomicus individualista, regido por una racionalidad instrumental de medios y fines, y a la empresa capitalista orientada por el lucro, caracterizada por su organización vertical y por la explotación de los "recursos" humanos y naturales. No obstante, en ciertos espacios sociales se sugiere transitar de la econo-mía - como negación de lo mío/nuestro, así como de la diversidad y de la vida- a las eco-sí-mías, lo que no se limita a una variación semántica, pues alude a propuestas y prácticas de diferencia o diversidad económico/cultural orientadas a la reapropiación de lo nuestro y de numerosos intercambios relacionales, vitales y solidarios. Estos se realizan a través de cooperaciones múltiples en lugares reorganizados para la vida comunal y en contextos de diferencia, singularidad y heterogeneidad, como anota Quijano-Valencia (2012), recuperando el aporte del líder indígena ecuatoriano Miguel Guaira Calapy (2005).

Así pues, en el patrón de poder moderno, colonial y capitalista prima una racionalidad instrumental, orientada por el cálculo y la eficiencia, en la cual los fines justifican los medios, que está despojada de toda consideración ética o estética y la cual se impone como criterio único de verdad. Por su parte, el buen vivir y la solidaridad económica nos hablan 
de la necesidad de cuestionar dicha racionalidad y reivindicar las experiencias que se rigen por racionalidades alternativas, reproductivas, solidarias y liberadoras.

La noción de racionalidad refiere a un conjunto de creencias, ideas, imágenes y discursos que orientan las acciones sociales; justifica la forma en que se vive en sociedad. Existen distintas maneras de vivir; sin embargo, se ha legitimado como universal y única la racionalidad instrumental; las reflexiones de Max Weber contribuyeron a esto. Este autor introduce dos conceptos de racionalidad: en primer lugar, uno asociado con un creciente dominio teórico de la realidad por medio de conceptos cada vez más precisos y abstractos y, en segundo lugar, otro entendido como una consecución metódica de un fin práctico y determinado mediante el cálculo cada vez más preciso de medios adecuados (Germaná, 2002). Ambos conceptos apuntan al desencantamiento del mundo a partir de un creciente proceso de intelectualización y racionalización, lo que significa que todo puede ser dominado mediante la previsión y el cálculo; se trata pues de una racionalidad instrumental de medios y fines, regida por un criterio de eficiencia. No existen ya, como para el "salvaje", poderes ocultos o imprevisibles, y se abre así paso a la modernidad/colonialidad capitalista ${ }^{4}$. Se impone una racionalidad instrumental "poseída únicamente de las urgencias del capital, de la productividad, de la eficacia de los medios para fines impuestos por el capital" (Quijano, 1988, p. 18), la cual supone un individuo racional que busca la utilidad máxima a partir del criterio básico del uso eficiente de "medios" o "recursos". Weber revisa la especificidad de esta racionalidad, y sostiene que esta particularidad es reflejo de la superioridad evolutiva de Europa, de manera que desde una lectura eurocéntrica del cambio social, esa racionalidad se impone como única y universal (Germaná, 2002; Nájera, 2012).

\footnotetext{
4 Quijano identifica dos racionalidades en disputa asociadas a la modernidad: la instrumental, que se impuso como la dominante y la liberadora o histórica. La primera alude a lo racional como lo útil desde la perspectiva del dominante, por lo que se registró una pronta asociación entre razón y poder; en tanto que la segunda refiere a los fines, que sería la liberación, la promesa de una existencia social racional, sin jerarquías, arbitrariedad u oscurantismo, rasgos de las monarquías absolutas y la Iglesia del momento (Quijano, 1988).
}

Entonces, tanto el buen vivir como la solidaridad económica encarnan racionalidades reproductivas, solidarias y liberadoras - solidarias con la naturaleza y liberadora de las personas- (Marañón, 2014). Las experiencias de solidaridad económica se caracterizan por articular los medios con los objetivos, al ser unidades de producción y consumo de forma simultánea; por tomar a los ingresos monetarios como medios para elevar las condiciones de vida familiar y de la colectividad, en vez de como fines en sí mismos; por valorar los bienes producidos por su capacidad de satisfacer necesidades, de manera que se valora la diversidad; por organizar a la producción con base en relaciones de reciprocidad, entendidas como un intercambio de fuerza de trabajo y de trabajo sin que se necesite el mercado, por lo que tienden a la desmercantilización, y por no reducir a las necesidades y satisfactores a cuestiones materiales, e incluir a necesidades de orden espiritual y afectivo (López y Marañón, 2013).

Sin embargo, el buen vivir y la solidaridad económica, con sus racionalidades alternativas, son proyectos y experiencias que se desenvuelven en un contexto donde prevalece la racionalidad instrumental; coexisten con las prácticas y el imaginario de la economía hegemónica y el desarrollo, y están con éstas en relaciones de complementariedad y conflicto. Son racionalidades en disputa y esto es lo que interesa señalar en el estudio de caso: la forma en que coexisten el buen vivir y la solidaridad económica con el desarrollo y la eco-no-mía en el municipio de Villa del Carbón, México.

\section{Villa del Carbón: características principales}

En Villa del Carbón existen experiencias que hablan de la solidaridad económica y el buen vivir; pero para abordarlas y dar cuenta de las racionalidades en disputa, es necesario contar con algunos elementos de su contexto local y regional.

Se trata de un municipio localizado al noreste del Estado de México (Edomex), a una distancia aproximada de 90 kilómetros de la capital del país. Según los criterios del Instituto Nacional de Estadística, Geografía e Informática (Inegi, s. f.), es un municipio eminentemente rural, pues de acuerdo con la última información censal del 2010, de sus casi 45 mil habitantes, el $62 \%$ vive en localidades menores a 2500 habitantes; sin embargo, por su ubicación, Villa del Carbón se ve amenazada por el continuo 
crecimiento de la Zona Metropolitana del Valle de México (zmvm) ${ }^{5}$.

El municipio ha registrado importantes cambios en su estructura económica durante las últimas décadas: para 1990 aún predominaban las actividades agropecuarias, pero para el 2000 ya prevalecían las actividades comerciales y los servicios orientados hacia el turismo (Zariñan, 2011); también, recientemente, las actividades de ecoturismo en el municipio, debidas a sus bienes naturales, han cobrado importancia (Ricardo Martínez, 23 de octubre de 2014, comunicación personal; Carlos Romero, 24 de octubre de 2014, comunicación personal). Sus áreas boscosas ocupan entre el 47 y el 57\% del territorio municipal. Esta riqueza forestal lo ubica como el cuarto productor forestal a nivel estatal (Ayuntamiento de Villa del Carbón, 2013). También existen importantes bienes hídricos: cuenta con cuerpos de agua, como las presas Llano de Zacapexco y Taxhimay; además, por la topografía, se generan escurrimientos intermitentes que convergen y forman ríos y manantiales. Esta zona boscosa brinda servicios ambientales de gran importancia a toda la ZMvM, en términos de captación de carbono, de regulación de temperaturas y de recarga acuífera; sin embargo, sus bienes naturales no están exentos de amenazas: el deterioro, tala y erosión de zonas forestales al norte, poniente y sur del municipio, así como la contaminación de los bienes hídricos, son algunos de los problemas más importantes.

Internamente, en Villa del Carbón se identifican dos espacios: la llamada zona alta - que es la que concentra la superficie boscosa, donde se alcanza una altitud máxima de 3600 metros sobre el nivel del mar en el Cerro de la Bufa - y la zona baja — con una altitud de 2300 metros sobre el nivel del mar-; es en ésta última donde existe población indígena otomí o ñhäñhú como ellos se autodenominan ${ }^{6}$. Aunque se

5 Esta zona es un espacio urbano que incluye a la Ciudad de México y se extiende a 60 municipios contiguos (59 del Edomex), que han sido incorporados a esta región y su área de influencia; entre estos hay una alta integración socioeconómica. Es uno de los conglomerados más poblados del mundo, con más de 20 millones de habitantes, contabilizados en el 2010.

6 Los primeros otomíes o hñä hñü eran nómadas y recolectores. Con el tiempo, fueron dominados por los aztecas. A la llegada de los colonizadores, las tierras fueron parte de las haciendas franciscanas. La palabra otomí proviene del náhuatl otocac, "que camina”, y mitl, "flecha", porque los otomíes eran grandes cazadores; también fue usado en términos despectivos por los aztecas como sinónimo de sucio y flojo. Actualmente se encuentran dispersos en varios estados del país y, bajo criterio de identificación lingüística, en el 2015 existían casi 308 mil hablantes de otomí -4\% de la pobla- reconoce la herencia de esta comunidad en todo el municipio, que se vea como algo positivo, desde las racionalidades en disputa, es algo reciente: por un lado, en la racionalidad utilitarista, lo indígena es abrazado para conseguir recursos de las instituciones a cargo de los asuntos indígenas de manera paternalista; por otro, lo indígena es asumido desde una auténtica reivindicación identitaria: “Tu raíz, tu cultura, tu lengua, tus costumbres, tu persona ... lo que me identifica como ser humano, quien soy, mis valores, raíces, principios, mi entorno ... no voy a cambiar mi forma de ser aunque cambie de ropa" (Armando Aparicio, 23 de octubre del 2014, comunicación personal). En la práctica, estas racionalidades se cruzan; aunque hay una predominancia de la racionalidad instrumental, pues el imaginario del desarrollo y el progreso está muy manifiesto: "Hay que bajar el desarrollo a las comunidades" (Armando Aparicio, 23 de octubre del 2014, comunicación personal), y en general, lo indígena es identificado exclusivamente con el lenguaje; además, aún son comunes situaciones discriminatorias contra los indígenas, principalmente en la cabecera municipal: "Se les degrada y se les sobaja ... [cuando] se les debería admirar, respetar [pues] también tenemos esas raíces, esa sangre, ese origen" (Guillermina Cruz, 23 de octubre del 2014, comunicación personal).

La Flor en el Manantial es un documental en el cual se recupera la memoria ritual y la tradición oral de los otomíes en el municipio y en el cual se alude a las relaciones coloniales ${ }^{7}$ :

"Somos un pueblo viejo con las manos en la tierra, con los ojos en el cielo... pero un día llegaron otros hombres y nos arrinconaron en las barrancas y las peñas, dejándonos sin tierra buena, conquistando nuestros cuerpos. Nos hicimos carboneros, y fuimos

ción nacional hablante de idioma indígena-, de los cuales se estima que más de 100 mil están en el Edomex. La industrialización y urbanización de esa entidad -y el colonialismo y racismo- han alterado drásticamente su hábitat milenario y transformado sus formas de vida, lo que los ha llevado a combinar la agricultura con otros trabajos en las ciudades: comercio ambulante, albañilería, obreros industriales, etc.; empero, mantienen un conjunto de ceremonias y rituales que los identifica como otomíes (Maqueda 2011; Barrientos, 2004).

7 Carlos Hernández (2011), quien realizó el citado documental, hace una recuperación de la tradición oral sobre la forma en que se concibe el cosmos y la relación de lo humano con lo sagrado en un pueblo otomí vecino, Magú, con el que las comunidades otomíes de Villa del Carbón guardan mucha relación. 
arrieros de vigas y tierra negra. Cuidamos nuestras borregas y nuestros puercos y caballos, nuestros guajolotes, nuestras gallinas. Y nos gritaban que éramos indios, marcados a fuego por su soberbia castellana. Y fueron siglos que vivimos apenas dejándonos ver. En las tierras más secas. En las milpas más inútiles. En las barrancas más duras. Pero somos otomíes. Somos fuertes y resistimos" (Hernández, 2014).

La identidad también es equiparada con la conciencia comunitaria, el reconocimiento "de lo que se es y lo que se puede ser, mirando la complejidad y variedad de circunstancias y culturas" (Armando Aparicio, 23 de octubre de 2014, comunicación personal), lo que apunta a un auténtico diálogo intercultural.

En la zona alta legalmente existen una comunidad indígena y un ejido de importancia, ambas formas de aprovechamiento social de la tierra. Como parte del proceso de restitución y dotación de tierras del México posrevolucionario, la comunidad indígena pidió el reconocimiento de sus tierras en 1916, amparándose en los títulos primordiales otorgados por la Corona en 1559; pero, como no se daba una resolución, se optó también por solicitar una dotación, y en 1927 se conformó el ejido de San Gerónimo Zacapexco con 728 hectáreas, que se amplió en 1937 con 1.886 hectáreas más. Nuevamente, en 1954, se pide el reconocimiento de la comunidad, el cual llegó hasta 1970, cuando se confirma una superficie de 8825 hectáreas para beneficiar 1092 comuneros; empero esa resolución se ejecuta parcialmente una década después, cuando se entregaron 6555 hectáreas. En 1998, se solicitó una nueva regularización, lo que culminó recién en 2003 cuando se actualizó el padrón y se reconoció una superficie de 6774 hectáreas, de las cuales el $49 \%$ se parceló y el 51\% restante son tierras de uso común (Mendoza, 2004). A pesar de que se habla de "propiedad" colectiva, se sostiene que los ejidos y comunidades decretados en el siglo xx apuntan ya al derecho individual, pues antes las comunidades incluían todas las tierras agrícolas a las cuales tenían derecho al uso y disfrute todos los miembros de la comunidad: "Se otorga dominio a un grupo de personas quienes son los únicos beneficiarios. Es decir, se pasa del derecho comunal de todos al derecho individual" (Mendoza, 2004, pp. 20-21). No obstante, se plantea que la superficie de uso común es tal que "puede ser el sustento de la comunidad" (Mendoza, 2004, pp. 20-21), y es en ese sentido que la comunidad se encarga de gestionar un proyecto de ecoturismo en la presa del Llano de Zacapexco, una de las experiencias de solidaridad económica identificadas, la cual será abordada en el siguiente apartado, junto con otras iniciativas colectivas.

En la parte baja es donde se concentra la población ñhäñhú. Esta zona, en general, ha mantenido una vinculación mayor con un municipio vecino Tepeji del Río, Hidalgo-, que con su cabecera municipal; además, esta zona sufrió un profundo proceso de desintegración, no solo físico, sino cultural, en aras del "desarrollo" (Carlos Hernández, 20 de octubre del 2014, comunicación personal; Jorge Becerril, 23 de octubre del 2014, comunicación personal). El poblado, conocido hasta los treinta como San Luis de Las Peras, fue desmembrado en dos barrios, San Luis Taxhimay y San Luis Anáhuac, pues se decretó su inundación en 1934 para la construcción de una presa para irrigar los terrenos del estado de Hidalgo: "Pueblo viejo, San Luis de las Peras, el que se inundó en contra del deseo de sus pobladores, el que fue sumergido en 42749 millones de metros cúbicos de agua [...] un peón sacrificable en el juego del progreso del país" (Maqueda, 2011). Se registró entonces un proceso de desestructuración de los modos de vida de la comunidad, el campo fue abandonado y se intensificaron los procesos migratorios nacionales e internacionales: "En cada casa de San Luis las familias están separadas irremediablemente, se han desgarrado los lazos de esta comunidad, se fueron los muchachos y los viejos se quedaron en el campo y siguen sembrando" (Maqueda, 2011). Las familias de la zona baja hace tiempo no pueden vivir solo de la agricultura - "antes el campo daba para comer todo el año" (Armando Aparicio, 23 de octubre del 2014, comunicación personal) - , de manera que tienen que diversificar sus actividades productivas. Las principales fuentes de ingresos de la población en San Luis son la agricultura, el aprovechamiento forestal, la ganadería, la minería y la pesca dentro de la zona, y, fuera, están la maquila, la construcción y, en menor medida, el comercio y los servicios (Maqueda, 2011). Se han realizado algunos intentos por impulsar proyectos colectivos para mejorar las condiciones de vida de los habitantes de la zona, entre estos, talleres de costura, invernaderos, talleres para industrializar alimentos, cooperativa de ecoturismo, pero estos intentos no han prosperado por varias razones, las cuales serán abordadas en el apartado que sigue, solo cabe adelantar que se trata una vez más, de un choque de racionalidades. 
Además, las acciones impuestas por el gobierno están impregnadas de actitudes clientelares y paternalistas, pues para terminar la contextualización del estudio de caso, no está de más mencionar que el Edomex, al que pertenece Villa del Carbón, ha sido gobernado de manera ininterrumpida por el Partido Revolucionario Institucional (PRI) desde $1925^{\circ}$, y se ha perpetuado de esa manera gracias a las relaciones paternalistas que se han establecido con las autoridades locales-comunales y, en general, con sus votantes. Destaca, además, la presencia de la familia Barrera, oriunda de Villa de Carbón y de adscripción priísta, tanto en el ámbito local como estatal, quienes desde los espacios de poder político que ocupan también van reproduciendo relaciones clientelares y paternalistas (Carlos Hernández, 20 de octubre del 2014, comunicación personal).

Un ejemplo de esto es el acuerdo que se estableció entre algunos comuneros de San Gerónimo Zacapexco y los distintos niveles de Gobierno para avalar que una autopista pase por el Cerro de la Bufa, principal pico de Villa de Carbón, bosque de coníferas y zona de uso común. La autopista TolucaNaucalpan, que atraviesa el Parque Otomí-Mexica, área protegida con categoría de Santuario del Agua ${ }^{9}$, y que pretende conectar el área de mayor plusvalía del Edomex (Huixquilucan) con la capital del país, fue aprobada en el 2007 por el entonces gobernador del Edomex y actual presidente del país, Enrique Peña Nieto, y concesionada a un empresario amigo suyo, Juan Armando Hinojosa Cantú (Cervantes, 2015; Mendoza, 2016); las obras se iniciaron en 2013. En Villa del Carbón, las opiniones se encontraban divididas, pues algunos comuneros sostenían que el proyecto carretero afectaría la zona de recarga, otros alegaban que la autopista no los beneficiaría. Al momento de las entrevistas ya se habían realizado siete asambleas para discutir el tema y se sostenía que las

8 De hecho, el antecedente del PRI, el Partido Nacional Revolucionario, se funda formalmente recién en 1929. Surgió como un partido para unificar las distintas fuerzas revolucionarias, y dar estabilidad al país. En 1938, se transforma en un partido de masas (Partido Revolucionario Mexicano) con la formación e incorporación al partido de las organizaciones campesinas y obreras. Desde 1946 es el PRI, quien fue el partido hegemónico hasta el 2000, y el cual está de vuelta en la presidencia desde 2012.

9 En palabras del gobernador del Edomex, se trata de una "autopista verde con una longitud de $39 \mathrm{~km}$ que incluye áreas con bosques naturales e inducidos, árboles frutales, cortinas rompevientos y cuerpos de agua" (Ávila, 2014). autoridades comunales estaban exigiendo que se escucharan sus posiciones:

Sí nos están escuchando... de hecho el comisariado de bienes comunales... está haciendo todo lo posible porque de alguna manera se entienda el sentir de la gente y que se pueda modificar ese trazo... y se está pidiendo un entronque... se busca que exista una salida a Villa del Carbón, porque de que nos sirve una autopista... la gente ahorita está tranquila esperando a ver si se modifican las cosas... pero si no se modifica creo que si existirá un problema social importante (José Juan Martínez Villanueva, 28 de septiembre del 2014, comunicación personal). <Fin de cita $>$

Como en el caso de la presa Taxhimay en la zona baja, el proyecto carretero no está pensado para el bienestar de las comunidades, sino para el de las empresas constructoras y la población "acomodada". Otro peón sacrificable. En comunidades como San Francisco Xochicuautla -Lerma, Edomex, comunidad que también se reivindica como otomí- se mantuvo una férrea resistencia al proyecto: en mayo del 2014 se consiguió un amparo del Tribunal Agrario para detener la obra, lo que anuló la asamblea de comuneros que avaló la obra; sin embargo, la empresa constructora regresó en octubre y en noviembre de ese año se registró un enfrentamiento entre comuneros y empleados de la constructora, respaldados los segundos por la policía estatal. En junio del 2015, nuevamente, entró la maquinaria de la empresa, y, para entonces, ya se habían afectado al menos dos kilómetros del bosque (Cervantes, 2015). De manera reciente (11 de abril del 2016), mientras se escribe esta reflexión, se derribaron casas en Xochicuautla, a pesar de la existencia de amparos (Mendoza, 2016).

Este ejemplo ilustra con nitidez la tensión entre racionalidades: un proyecto carretero al que no le importa devastar territorios y afectar tanto a sus habitantes como a sus formas de vida, historias de destrucción que se repiten en el municipio, en aras del progreso/desarrollo.

\section{El buen vivir y solidaridad económica en Villa del Carbón}

En Villa del Carbón, existen experiencias familiares y colectivas que hablan de la solidaridad económica y el buen vivir, aunque no se identifiquen como tales.

Una de estas experiencias es la de los Productores Rurales Piedra Grande El Ocotal, la cual tiene la 
propuesta más integral. Se trata de un grupo de agroecología de reciente formación que aglutina a unas diez familias, el cual se organizó a partir de la implementación en la región del Proyecto Estratégico para la Seguridad Alimentaria (PESA) ${ }^{10}$, al que le reconocen grandes bondades: desarrollo de capacidades; promoción del cuidado de la naturaleza, de la buena alimentación y de la organización, e incluso del trabajo colectivo -la reciprocidad-y de la convivencia:

Con el PESA volvimos a entender lo que es la convivencia del campo. Yo recuerdo cuando era niño, mis papas y mis abuelitos nos llevaban al campo e íbamos a sembrar un terreno y después con otra familia y al siguiente día con la otra y así. Las abuelitas, las mamás, llevaban la comida, llevaban todo, y comíamos todos en convivencia; eso, eso ya no se hace hoy en día... fue algo muy importante, para organizar a las personas, volver a fomentar la convivencia entre vecinos, amigos, familiares, el PESA fue una herramienta (Lamberto González, 26 de octubre del 2014, comunicación personal).

La convivencia se amplía además a lo no humano. Se reconocen similitudes - una planta bien alimentada es como una persona, de hecho aquí lo primero es que hay que alimentar el suelo" (Lamberto González, 13 de septiembre del 2014, comunicación personal) - y se establece la relación y la complementariedad entre lo humano y lo no humano. Una integrante del colectivo comenta: "Acá la apicultura estaba bien, pero con los plaguicidas se mueren las abejitas. En lugar de usar los métodos de la agroecología, que implica un poco más de trabajo, echan los

10 La Organización de las Naciones Unidas para la Alimentación y la Agricultura creó el PESA en 1994 para incrementar la producción de alimentos y reducir el hambre y la desnutrición. Al inicio buscaba promover y divulgar tecnologías sencillas, además de económicas, para mejorar la producción y los ingresos de las familias de agricultores pobres. En México se implementó desde el 2002, con el fin de contribuir al desarrollo de capacidades, individuales y familiares, en comunidades de alta marginación, para incrementar la producción agropecuaria, innovar los sistemas de producción, desarrollar los mercados locales, promover el uso de alimentos, y la generación de empleos para lograr su seguridad alimentaria y el incremento en el ingreso. En el diseño del programa se asoma la lógica evolucionista propia del eurocentrismo; el fin último es que los campesinos se vuelvan agricultores comerciales. Se impone la racionalidad instrumental: "El pequeño campesino en un inicio tiene como objetivo la autosuficiencia alimentaria, evoluciona con la venta de excedentes, hasta lograr la organización de campesinos-agricultores comerciales con alta tecnología y lograr ser un eslabón de las cadenas productivas" (Sagarpa, 2012, p. 26). herbicidas que les entrega el gobierno" (Nadia Reyes, 26 de octubre del 2014, comunicación personal). Por su parte, otro socio agrega:

Con los sistemas agrosilvopastoriles entendimos que puede convivir bosque, ser humano y ganado de una manera ordenada... pastorean pero cuidando que los animales no perjudiquen los árboles para que puedan hacer su trabajo, que el agua se filtre y haya retención de humedad (Lamberto González, 13 de septiembre del 2014, comunicación personal).

En el control de las llamadas "plagas" y "malezas" también se advierte esa racionalidad otra:

Cuando llega a presentarse un caso de enfermedad, preparamos algunas infusiones de las mismas hierbas que hay en la región o ponemos plantitas trampas; por ejemplo, si nos llega un insecto que nos esté perjudicando alguna lechuga, el jitomate, ponemos una planta de la que más le guste y ahí se queda quietecito, está come y come, échale comida y ya no les va a molestar a las demás. Los insectos están contentos porque aparte son parte del equilibrio, es algo fundamental, el día que ya no haya insectos, no va haber floración, no va a haber frutos... Tenemos que aprender a convivir con esto, que mucha gente lo ve como una plaga o como maleza, no, para nosotros dejó de haber plagas, dejó de haber maleza, todo lo controlamos de una manera natural (Lamberto González, 13 de septiembre del 2014, comunicación personal).

La agroecología en este colectivo es pues aprehendida desde los contextos específicos y la diversidad, sin que esta se convierta en una camisa de fuerza, a diferencia de la agricultura convencional, que abstrae esas diferencias e impone su lógica como la única legítima: "Mi hermano produce de una forma y yo produzco de otra, pero enfocada a lo mismo, con los mismos principios... [entre ellos] el respeto" (Lamberto González, 26 de octubre del 2014, comunicación personal).

En sintonía con los principios de la agroecología, el grupo busca no solo la seguridad alimentaria, sino la soberanía en ese respecto, y en ese sentido apuntan hacia la autonomía y la desmercantilización, pues tienen claro que hay que romper con la dependencia de insumos y alimentos.

De eso se trata, cerrar el círculo, no depender de casi nada de fuera, la mayoría que lo produzcamos noso- 
tros... por ejemplo, para los abonos, un productor debe tener la seguridad de que tiene por lo menos un $80 \%$ de los productos para hacer sus abonos (Lamberto González, 26 de octubre del 2014, comunicación personal). $<$ Fin de cita $>$

Otra de sus consignas es la protección y recuperación de semillas, pues en esto ven un asunto estratégico, ya que hay una recuperación de la memoria histórica al recordar que se trata de prácticas realizadas por sus antecesores, y se reconoce que en estas existe una racionalidad reproductiva; se rompen relaciones de dependencia con los gobiernos clientelistas para la obtención de insumos, y además identifican la dignificación del campesinado en esta acción:

El que tenga las semillas tiene el poder... la gente sobre todo el campesino no debe dejar perder sus semillas. Yo recuerdo que mi papá cada año separaba sus semillas y las guardaba. Sembraba, pero aparte siempre guardaba una parte importante de sus semillas, porque a veces venia un mal temporal y se le acababan, entonces decía 'no, no hay problema porque ya tengo semillas para sembrar el próximo año'. Ahorita no, la gente se tiene que esperar hasta que el Gobierno mande las semillas, las subsidia, y la gente perdió todas sus semillas... Nos interesa mucho recuperar la dignidad del campesino, pero con conocimiento. Que la gente ya empiece a recuperar la dignidad porque eso es dignidad, que empiece a recuperar sus semillas nativas de la región porque se están perdiendo, entonces al perder las semillas quiere decir que somos un país conquistado y un país conquistado no sirve para nada (Lamberto González, 13 de septiembre del 2014, comunicación personal).

En el resguardo de semillas también se ve una forma de convivir con los desastres naturales, los cuales son percibidos de otra manera. Hay una racionalidad solidaria, no se trata de dominar a la naturaleza, sino de entenderla: "Tenemos problemas cuando llega a caer una helada, una granizada, pero pues es normal, creo que es parte de la naturaleza, todo tiene un ciclo, viene una helada y termina lo verde. Por eso tenemos que guardar semillas" (Lamberto González, 13 de septiembre del 2014, comunicación personal).

Los integrantes de la experiencia de El Ocotal tienen claro que lo primero es resolver las necesidades de alimentación, propias y de sus familias. Se rigen pues por una racionalidad reproductiva, pero también buscan ampliar los espacios de intercambio de sus excedentes. Así mismo, en estos espacios tampoco se busca "maximizar la ganancia", se reconocen no solo como lugares de intercambio de productos, sino también como espacios de diálogo para difundir el potencial liberador de la agroecología y sus productos, frente a los alimentos estandarizados y producidos de forma convencional:

Estamos ahí pero se vende muy poco... tenemos poco tiempo y la gente es muy difícil que le compre a uno, prefieren irse a centros comerciales donde ven cantidades, no saben cómo lo están produciendo y tampoco le van a explicar, pero la gente ahí va y compra. Lo que es productos orgánicos es muy difícil que la gente los compre, de hecho hay que hacer labor de convencimiento... lo que estamos haciendo es que a los niños que se acercan, las amas de casa, poco a poco les vamos platicando cuál es el motivo de estar ahí (Lamberto González, 26 de octubre del 2014, comunicación personal).

Así, la experiencia habla de una racionalidad solidaria con la naturaleza; desde la agroecología se reconoce la relacionalidad y complementariedad entre las personas y esta. También de una racionalidad liberadora, porque con las prácticas agroecológicas se busca romper con la dependencia alimentaria y se tiende a la desmercantilización; además, los espacios de intercambio se aprovechan para dar a conocer y promover los beneficios de los alimentos orgánicos, y alertar sobre la necesidad de cuidar la tierra, la naturaleza. Se tratan de prácticas que van a contracorriente, pues reconocen que la gente no es proclive a consumir sus productos y prefieren ir a los supermercados, espacios despersonalizados, símbolos del "desarrollo"; además, son conscientes del desinterés de las autoridades por promover proyectos de este tipo:

Esto de la agricultura orgánica no tiene fin, nosotros tenemos los recursos; pero también nos hace falta tecnología, cómo aplicarla, para eso pues están los investigadores. Aquí es donde las autoridades tienen que jugar un papel muy importante, lo deben de fomentar... las autoridades hacen caso omiso, ahorita a nosotros ya nos están apoyando porque estamos haciendo ruido, pero hace como un año que nadie nos conocía (Lamberto González, 13 de septiembre del 2014, comunicación personal). >

A pesar de las dificultades, se reconocen como un grupo que tiene claro a dónde ir, se trata de la 
búsqueda del buen vivir, aunque no se explicite de esa manera: "Yo creo que nos estamos llevando bien, porque somos gente que no busca riquezas, nosotros buscamos tener buena alimentación, que tengamos buen aire, que tengamos un aire de calidad, una agua de calidad" (Lamberto González, 26 de octubre del 2014, comunicación personal).

Otra de las experiencias reconocidas en Villa del Carbón es el Parque Ecoturístico Presa del Llano, donde se ofertan espacios para campismo, renta de cabañas, paseos en lancha, pesca deportiva y senderismo. Hasta 1996 el agua de la presa era para riego: "Antes era nada más para el cultivo... principalmente maíz y trigo, avena, chícharo, haba, que es lo más elemental que se produce aquí, más que todo por el clima" (Isaías Peralta, 12 de septiembre del 2014, comunicación personal). Antes del 2002, la presa estaba en manos del municipio, pero, desde entonces, ha sido manejada por la comunidad de San Gerónimo Zacapexco, que cuenta con 1092 comuneros reconocidos legalmente. A partir de ese momento empezaron a construir las instalaciones necesarias para atender a los visitantes. Los recursos que se generan de la presa sirven para incrementar esa infraestructura y para pagar a los doce trabajadores directos que tiene el parque.

En términos organizativos, existe una estructura para gestionar el parque, pero esta se encuentra supeditada a la asamblea comunal: "Aquí hay administración independiente... pero los mismos comuneros deciden quién se va a quedar como encargado del parque... tenemos un consejo de comuneros que es el que nos está vigilando a nosotros" (Isaías Peralta, 12 de septiembre del 2014, comunicación personal).

Esa administración independiente busca realizar su trabajo "lo mejor posible", pues, por un lado, se siente muy comprometida con la comunidad, dado el voto de confianza que esta tiene con esta administración, y, por otro, hay una exigencia con los visitantes, al reconocerse como la imagen del parque: "Tratamos de hacer nuestro trabajo lo mejor posible ya que la confianza que nos dan los comuneros es muy grande... nuestra iniciativa de trabajo es la proyección que damos del parque hacia los turistas, nosotros somos la imagen del parque" (Isaías Peralta, 12 de septiembre del 2014, comunicación personal).

El parque está dentro de una zona protegida, por lo que su aprovechamiento se encuentra regulado. En las disputas por las tierras, mencionadas en el apartado previo, existía además la oposición de los supuestos propietarios privados, que contaba con la ayuda de la oficina municipal, a que la comunidad aprovechara el bosque de pino y encino; por esta razón, la comunidad buscó reafirmar sus derechos, ordenar el aprovechamiento y procurar su conservación (Mendoza, 2004). En las autoridades municipales y los propietarios individuales se plantea una tensión entre conservar y explotar, sin una aparente posibilidad de compaginar aprovechamiento y conservación. El proyecto ecoturístico busca salvar esta supuesta contradicción:

Una de las principales cosas, es la preocupación del agua... nos reunimos con Conagua ${ }^{11}$ para ver cómo cuidamos todo, cómo podríamos crecer y hacer una potencia, mas no destruyendo el bosque, la zona del manantial. No vamos a quitarlo, vamos a esforzarnos para que siga así, es aquí donde se dan los hongos (Isaías Peralta, 12 de septiembre del 2014, comunicación personal).

En la preocupación por hacer un buen manejo de su bosque y agua, se reconoce un componente generacional y se amplía más allá de la comunidad jurídicamente reconocida. Se trata de defender el derecho a la vida: "Tenemos nuestros hijos, bueno no eres comunero pero también tienes derecho, tienes derecho simplemente porque es para tener un mejor servicio de agua. Que en lugar de que nos esté disminuyendo, nos vaya incrementando" (Isaías Peralta, 12 de septiembre del 2014, comunicación personal).

En la relación con los visitantes, también se busca fomentar la concientización y la colaboración, reconociendo que algunos de ellos llegan al lugar con una actitud individualista y monetarista, y suponen que si se paga, se puede contaminar: "Hay personas, como todo, personas muy ordenadas y personas que dicen 'yo pago, tengo derecho a todo' pero pues nunca se han puesto a pensar que en lugar de ayudar destruyen" (Isaías Peralta, 12 de septiembre del 2014, comunicación personal).

Sobre el trabajo colectivo, se menciona que es algo que se ha venido perdiendo, aunque entre las familias se mantiene; además, se sostiene que las reforestaciones se hacen de manera colectiva y sin recibir una remuneración, y que al interior del parque se recurre a las faenas:

11 Comisión Nacional de Agua, la autoridad en materia de agua del país. 
Cuando es necesario jalar, ahora, si valga la expresión $[$ sic], juntarnos todos y hacer una sola cosa, que sea como barrer senderos y recolectar basura, todos nos vamos. Aquí no hay administrador, aquí no hay quien haga cabañas, aquí no hay mantenimiento: todos somos los mismos y así es (Isaías Peralta, 12 de septiembre del 2014).

La experiencia no está exenta de dificultades. Por ejemplo, aunque el parque está a cargo de la comunidad, existe cierta inconformidad, porque los beneficios no son visibles para todos los comuneros, y menos aún para los no comuneros; tampoco resulta del todo transparente la toma de decisiones, por lo que se sugiere establecer mecanismos de comunicación entre los administradores del parque y la asamblea comunal (Mendoza, 2004). No obstante, como se comentó en el apartado previo, las tierras comunales, entre estas, la presa, pueden ser el sustento de la comunidad ante la pulverización de las propiedades familiares, además, hay problemas de contaminación y agotamiento del suelo de manera que la agricultura campesina ya no garantiza la subsistencia familiar como lo hacía antes, por lo que se emprenden otras actividades, entre estas, la migración. En proyectos colectivos, como el parque ecoturístico, se ve la posibilidad de quedarse, se pugna el derecho a permanecer, a no migrar, y a disfrutar de una vida familiar, de un buen vivir:

Yo la verdad no me iría, porque vas a ganar dinero pero no ganas cariño...pierdes el cariño de tus hijos, no los ves crecer, el cariño de tu pareja porque no estás diario con ella... nosotros como padres salimos a buscar el pan y traerlo, pero nos perdemos de muchas cosas, de todas las vivencias de nuestros hijos y de toda la vivencia de nuestra familia... aquí hay muchas formas de ver la vida, pero hay que vivirla en unión, con tu familia (Isaías Peralta, 12 de septiembre del 2014, comunicación personal).

Así, se entretejen y tensionan racionalidades. El imaginario del desarrollo, del "bien-estar" material, del vivir mejor, impulsa a las personas a migrar, lo que se cruza con la necesidad y el deseo de permanecer y ser parte activa de una vida familiar y comunitaria.

La sociedad de producción rural (SPR) Silvicultores Unidos de la Cuenca del Alto Panuco (Sucap) es otra organización económica orientada a la conservación de bosques y al aprovechamiento forestal: a la producción de árboles de navidad, de especies con fines maderables y para la prestación de servicios ambientales hidrológicos. Como SPR se fundó recién en el 2007 con la participación de 126 socios - y una superficie de 120 hectáreas-, aunque desde 1998 se venía planteando la necesidad de que los comuneros y ejidatarios se organizaran, buscando incluir además a otros productores que jurídicamente no pertenecen a esos núcleos agrarios pero que dada su importancia, cuentan con el respaldo de las autoridades comunales y ejidales:

La mayor cantidad de personas de este grupo son de bienes comunales de San Gerónimo Zacapexco... algunos inclusive son de fuera de esta misma comunidad, pero esta es una ventaja que se tiene como organización, el que puedes incluir a personas que no sean del mismo núcleo... algunos son hijos de ejidatarios, algunos son avecindados que ya tiene parcelas aquí y algunos inclusive no son de adentro de la comunidad y el ejido... lo que se hace es solamente tener el soporte del ejido, el soporte legal... Realmente la representación de la comunidad lo que hace es ayudarnos para el seguimiento y el fortalecimiento del mismo grupo (José Juan Martínez, 28 de septiembre del 2014, comunicación personal).

De manera recíproca, por el respaldo recibido, la organización apoya las capacitaciones que se dan a otras comunidades del país con bienes forestales en San Gerónimo Zacapexco, en su calidad de comunidad instructora: "Lo que hacemos nosotros es participar con la comunidad en capacitar a la gente" (José Juan Martínez, 28 de septiembre del 2014, comunicación personal).

A pesar de la vinculación con los núcleos agrarios, Sucap cuenta con una estructura de autoridad propia:

La máxima autoridad de la organización es la asamblea general de productores. Hay una mesa directiva, que es la que representa los intereses del grupo, con un presidente, un secretario y un tesorero. Todos somos integrantes del grupo y obviamente la asamblea decide quien queda en esa representación. Hay un consejo de vigilancia que se encarga de verificar que realmente las cosas se hagan bien al interior y al exterior y hay una comisión interna, la que hace verificar el manejo del recurso (José Juan Martínez, 28 de septiembre del 2014, comunicación personal). 
A través de esta organización se han gestionado recursos de Probosque ${ }^{12}$ para que los socios establezcan plantaciones y puedan darles mantenimiento durante cinco años. A partir del quinto año, si se trata de plantaciones de árbol de navidad, ya se pueden comercializar; o bien, desde ese momento, pueden recibir ingresos por el programa de pagos por servicios ambientales hidrológicos al conservar áreas de bosque que permiten la recarga hídrica. Para la conservación de los bosques, se sostiene que los beneficios no son solo para la comunidad, sino para la sociedad en general, pues "se produce de alguna manera oxígeno por las plantaciones... se recargan los mantos acuíferos...estamos evitando que se erosione el suelo" (José Juan Martínez, 28 de septiembre del 2014, comunicación personal).

Por su parte, para los productores los beneficios son los "incentivos económicos" que los orientan a realizar actividades de conservación o de aprovechamiento sustentable frente al deterioro de la agricultura campesina:

Después de que eran bosques naturales, se hicieron parcelas agrícolas y ahora de parcelas hay unas que se vuelven a convertir en forestales... la verdad es que si nos ayuda bastante porque nos están dando un incentivo que no se obtenía de manera directa con la plantación de maíz, entonces nosotros lo vemos como algo viable (José Juan Martínez, 28 de septiembre del 2014, comunicación personal).

La comunidad cuenta con un plan de manejo forestal, que permite el aprovechamiento de tierra de hoja y madera en rollo. Pero se identifican varios problemas a superar: la deforestación, la infraestructura subutilizada, la tala clandestina y la falta de una cultura forestal de los comuneros (Mendoza, 2004). Con el fin de resolver estas dificultades, Sucap impulsa un conjunto de actividades colectivas:

De manera colectiva hacemos algunas faenas, en dos partes, faenas en las plantaciones y faenas en un proyecto que tenemos de un aserradero que estamos estableciendo... En las plantaciones hacemos recorridos, específicamente de inspección y vigilancia... para verificar que las zonas estén bien, tengan un

12 Protectora de Bosques del Edomex (Probosque) es un organismo público descentralizado vinculado a la Secretaría de Medio Ambiente del Edomex para promover el desarrollo forestal sustentable (http://probosque.edomex.gob.mx/acerca_probosque). mantenimiento adecuado pero que además no exista clandestinaje. En el caso del proyecto de aserradero hacemos cuestiones de mantenimiento, ya sea pintar la maquinaria, engrasar, y ahorita vamos hacer otra faena que es para cercar el predio, y bueno principalmente limpieza del lugar (José Juan Martínez, 28 de septiembre del 2014, comunicación personal).

Para la reactivación y habilitación del aserradero se ha contado con el apoyo de instituciones como la Comisión Nacional para el Desarrollo de los Pueblos Indígenas y la Comisión Nacional Forestal, además de las contribuciones de los socios: "Logramos adquirir con aportación de los productores este terreno" (José Juan Martínez, 28 de septiembre del 2014, comunicación personal).

Como en el proyecto del parque ecoturístico, en el del aserradero de Sucap también se fincan las esperanzas de permanencia en la comunidad, principalmente de los jóvenes, al generar opciones de trabajo e ingreso. Hay buenas expectativas en torno a esta iniciativa al identificar un conjunto de ventajas, como experiencia organizativa acumulada y jóvenes profesionistas:

Tenemos una ventaja nosotros, que casi todos lo que han sido representantes del comisariado están dentro del grupo, es gente que ya trae una experiencia y trabajo... ahora si ya sabe cómo hacer las cosas. La otra es que los hijos de los productores, que en algunos casos son profesionistas, han buscado ya cómo permanecer en el lugar pensando en que existe algo alternativo (José Juan Martínez, 28 de septiembre de 2014, comunicación personal).

Inicialmente se estableció un conflicto con los jóvenes, pues los comuneros estaban reacios a aceptar las propuestas y opiniones de estos; pero, gracias a la sensibilidad y el trabajo de estos, lograron impulsar proyectos conjuntos:

Tuvimos la oportunidad de estar estudiando fuera... de conocer mucho sobre la cuestión forestal... cuando terminamos la carrera, dijimos "bueno, nuestra comunidad tiene potencial, tiene muchos atributos que puedan ayudarnos a desarrollarnos profesionalmente". Eso fue lo que nos motivó a regresar, dijimos "vamos a hacer algo". Pero, trabajar con la gente y organizarlos, hacerlos entender que vamos por una sola línea es muy difícil. La gente nos decía que estábamos locos: nos decían "esos chamaquitos qué nos van a 
venir a enseñar”... Les decíamos “también queremos aprender de ustedes, queremos ver lo que ustedes han hecho toda la vida, pero también que aprendan de nosotros". Les decíamos "yo creo que si juntamos las dos partes podemos hacer algo bueno". Pero empezamos así poco a poco... A nosotros nos queda claro que hay que escuchar a la gente, hay que ponernos de su lado para que obviamente podamos forjar algo juntos, porque si nosotros llegáramos con una idea de imponer pues difícilmente vamos a avanzar (José Juan Martínez, 28 de septiembre del 2014, comunicación personal).

Asimismo, se ha identificado que el proyecto requiere la suma de esfuerzos, pues en su calidad de pequeños productores, de manera individual es poco lo que se puede lograr. Esta es una idea que se ha logrado transmitir a los productores:

¿Cómo fortalecemos el grupo?, ¿cómo vamos más allá? Ya se quitó la idea de me vas a dar 500 pesos ahorita y después otros 500 pesos, y voy a la tienda y ya se me acabaron. Realmente no me sirven de nada. Entonces con esos 500, de los 126 productores logramos hacer una cosita más grande y generar un beneficio adicional (José Juan Martínez, 28 de septiembre del 2014, comunicación personal).

Así mismo, están convencidos que con el aserradero se persigue un beneficio común: "los empresarios están viendo sus intereses y nosotros creemos que la diferencia que habría es el que el beneficio va a ser dividido entre todos los productores" (José Juan Martínez, 28 de septiembre del 2014, comunicación personal).

Existen otras iniciativas que se han impulsado, como el Centro Ecoturístico Monhüa (vendedores de pescado en Otomí), cooperativa conformada en el 2003 en la presa San Luis Taxhimay. El grupo inicial de 25 socios se dividió, y actualmente son 14. Desde el principio se planteó una tensión aparentemente irreconciliable entre los intereses del grupo y los de la comunidad. En el grupo se percibía que existía una "envidia y desconfianza hacia el grupo por parte de la mayoría de las personas de la comunidad debido a que ya estamos integrados en un grupo de trabajo realizando actividades diferentes a las de ellos" (Marcelino Ugarte, 27 de septiembre del 2014, comunicación personal), y desde la comunidad, se señala que el embarcadero es un negocio familiar "porque ni en la fiesta del santo patrón dan nada" (Maqueda,
2011). También existe un colectivo de mujeres de reciente conformación en la comunidad otomí de El Palomar. Inicialmente contaba con trece participantes; actualmente solo son tres, pues en el diseño del proyecto no se contemplaron las actividades cotidianas de las mujeres, por lo que este resultó para ellas una carga, más que una oportunidad.

Estos "fracasos", en general, son atribuidos a la actitud irracional de los beneficiados, a la falta de actitud empresarial; sin embargo, desde los planteamientos aquí desplegados, y en opiniones recuperadas en campo, son otras las razones, como que haya una posición defensiva que adoptan las comunidades las cuales han sido sistemáticamente engañadas y que culturalmente los proyectos de "desarrollo" no coincidan con las formas de vida de la comunidad (entrevistas a Michele Benítez y Jonás Mejía, 3 de octubre del 2014; Carlos Hernández, 20 de octubre del 2014; Beatriz Cruz, 25 de octubre del 2014; Jorge A. Becerril, 25 de octubre del 2014), de manera que se da un choque de racionalidades. Aun los proyectos "exitosos", como los presentados, son "evaluados" con base en una racionalidad instrumental y en una lógica del mercado, sin considerar sus especificidades como experiencias de solidaridad económica, por lo que surgen contradicciones entre esas prácticas y las propuestas de "desarrollo" enfocadas a vincularlas de forma utilitarista al mercado.

\section{Conclusiones}

El estudio de caso muestra la existencia de prácticas de solidaridad económica que buscan el buen vivir, a pesar de no ser nombradas como tales. Esas iniciativas tienen una racionalidad que se aleja de la económica instrumental, pues intentan obtener un bienestar colectivo, no la máxima ganancia individual.

Para alcanzar este objetivo, despliegan acciones e imaginarios que se diferencian de la visión dominante de economía que supone un homo œconomicus orientado por una racionalidad instrumental, con un comportamiento egoísta e individualista que busca el máximo bienestar material, y entiende al mercado como espacio básico de interacción social. Esa perspectiva ha llevado a desconocer o descalificar prácticas con racionalidades otras, como las presentadas.

En esas experiencias la naturaleza no es concebida como un objeto o un recurso, sino es la base que sostiene la vida, de manera que desarrollan sus actividades respetándola y cuidándola. Se tiende a la soberanía alimentaria y a la desmercantilización de los 
procesos productivos, pues se rompe con la dependencia de insumos y productos provenientes del mercado capitalista (alimentos, semillas, fertilizantes, etc.); se toman las decisiones de forma democrática, y se organiza el trabajo recíprocamente combinando lo individual y familiar con lo colectivo.

Sobre la reciprocidad, Sabourin (2003) sostiene que las sociedades campesinas son proclives a obtener excedentes para consumir o redistribuir, ya que, para "existir socialmente", se requiere dar; para dar, es necesario producir. Por eso, la reciprocidad genera, a través de la redistribución, una producción socialmente motivada, la cual va más allá de la satisfacción de las necesidades elementales de la población (subsistencia) o de la adquisición de bienes materiales por medio del trueque, lo que contradice la idea del conformismo de las poblaciones campesinas e indígenas.

Las experiencias de solidaridad económica recrean prácticas e imaginarios como el de la reciprocidad. No obstante, desde el imaginario del progreso/ desarrollo son considerados obstáculos, y, en ese sentido, más que potenciarlos van siendo debilitados por las políticas públicas que se conciben a partir de una racionalidad instrumental, las cuales, al no dar cuenta de las especificidades de las prácticas solidarias, chocan con las racionalidades reproductivas/solidarias/liberadoras de las iniciativas, al buscar insertarlas de manera utilitarista al mercado y forzarlas a adoptar un comportamiento empresarial, que muchas veces les resulta ajeno. Con esto, lo que se ha conseguido es desestructurar diversas prácticas que han sostenido la producción y reproducción en el mundo campesino, como la cooperación, el trabajo colectivo/comunitario, la ayuda mutua y otras expresiones de la reciprocidad.

Los rasgos de las prácticas de solidaridad económica, que encarnan racionalidades alternativas, racionalidades otras, deberían ser considerados para diseñar y aplicar políticas públicas de promoción y fortalecimiento. En lugar de forzarlas desde una racionalidad instrumental a perseguir la ganancia como si se trataran de proyectos empresariales capitalistas o bien de proyectos asistenciales. Esto exige, entre otras cosas, romper con el eurocentrismo que impone el imaginario desarrollista y una visión homogeneizadora que no reconoce otras formas de hacer economía y otras racionalidades, se limita a promover el trabajo asalariado y el mercado como espacio primordial de interacción social.

Es necesario, pues, reconocer que se trata de formas distintas de vivir, que resisten, se crean y recrean, y que son legítimas aunque se alejen del mercado y del estado - y su racionalidad instrumental-, con los que se establecen complementariedades, pero sobre todo tensiones. Son parte de la diversidad económico/cultural que la eco-no-mía intenta borrar.

\section{Agradecimientos}

Un sentido agradecimiento a Norberto Meléndez y a Rose Mary Herman. Gracias a ellos se propició el acercamiento a las experiencias y al municipio.

\section{Referencias}

Ayuntamiento de Villa del Carbón. (2013). Plan de Desarrollo Municipal 2013-2015.

Barrientos, G. (2004). Otomíes del Estado de México. MéxiCO: CDI/PNUD.

Cervantes, Jesusa. (2015, junio). Autopista Toluca-Naucalpan: amenazas y represión contra comuneros. Revista Proceso. Recuperado de: http://www.proceso. com.mx/408452/autopista-toluca-naucalpan-amenazas-y-represion-contra-comuneros

Escobar, A. (2014). América Latina en una encrucijada: ¿modernizaciones alternativas, posliberalismo o postdesarrollo. En P. Quintero (Comp.), Crisis civilizatoria, desarrollo y Buen Vivir (pp. 53-97). Buenos Aires: Ediciones del Signo.

Germaná, C. (2002). La racionalidad en las ciencias sociales. Lima: Fondo Editorial de la Facultad de Ciencias Sociales - UNMSM.

Gudynas, E. (2014). El malestar moderno con el buen vivir. En P. Quintero (Comp.), Crisis civilizatoria, desarrollo y buen vivir (pp. 127-153). Buenos Aires: Ediciones del Signo.

Hernández, A. (productor y director). (2011). San Francisco Magú. Voz fuerte: con la memoria en la piel (Documental). México: Ayuntamiento de Nicolás Romero/ MonteBajo.

Hinkelammert, F. y H. Mora. (2005). Hacia una economía para la vida. San José: DEI.

Inegi. (s. f.). Población rural y urbana. Recuperado de: http:// cuentame.inegi.org.mx/poblacion/rur_urb.aspx?te$\mathrm{ma}=\mathrm{P}$

López, D. (2016). Buen Vivir y solidaridad económica: la reciprocidad como eje básico de integración social entre las personas y con la 'Naturaleza'. En P. Quintero (Comp.), Alternativas descoloniales al capitalismo colonial/moderno (pp. 81-112). Buenos Aires: Ediciones 
del Signo.

López, D. y Marañón-Pimentel, B. (2013). Racionalidades y prácticas socioproductivas alternativas para el Buen Vivir. México: IIEC-UNAM.

Marañón, B. (2014). Crisis global y descolonialidad: la emergencia de una racionalidad liberadora y solidaria. En B. Marañón (Coord.) Buen Vivir y descolonialidad. Crítica al desarrollo y la razón instrumentales (pp. 2160). México: IIEC-UNAM.

Marañón, B. (2012). Hacia el horizonte alternativo de los discursos y prácticas de resistencias descoloniales. Notas sobre la solidaridad económica en el Buen Vivir. En B. Marañón (coord.) Solidaridad económica y potencialidades de transformación en América Latina. Una perspectiva descolonial (pp. 125-154). Buenos Aires: Clacso.

Marañón, B. y D. López. (2014). Racionalidad alternativa de las experiencias de solidaridad económica en México: apuntes para el diseño de políticas públicas. Estudios Agrarios, 57, 99-121.

Maqueda, L. (2011). San Luis Taxhimay, historia del desarraigo y supervivencia de un pueblo. Recuperado de http://sociologos-luz.blogspot.mx/2010/06/blog-post. html

Mendoza, R. (2004). La comunidad indígena de San Gerónimo Zacapexco: un largo camino para el reconocimiento de sus tierras. Revista de Estudios Agrarios, 27, 1-39.

Mendoza, V. (2016, abril). Irrumpe Higa con fuerza pública a Xochicuautla; derriba viviendas pese a amparos Revista Proceso. Recuperado de http://www.proceso. com.mx/436625/irrumpe-higa-fuerza-publica-a-xochicuautla-derriba-viviendas-pese-a-amparos
Nájera, E. (2012). Colonialidad del poder y racionalidades liberadoras. El Centro de Desarrollo Agropecuario: una experiencia prefigurativa hacia el buen vivir (Tesis de licenciatura en Sociología). UAM-Azcapotzalco, México, D. F.

Quijano, A. (1988). Modernidad, identidad y utopía en América Latina. Lima: Sociedad y Política Ediciones.

Quijano, A. (2014). Cuestiones y horizontes: de la dependencia histórico-estructural a la colonialidad/descolonialidad del poder (selección y prólogo a cargo de Danilo de Assis Climaco). Buenos Aires: Clacso.

Quijano-Valencia, O. (2012). EcoSImías. Visiones y prácticas de diferencia económico/cultural en contextos de multiplicidad. Colombia: Editorial Universidad del Cauca.

Sabourin, E. (2003). Dadiva e reciprocidade nas sociedades rurais contemporâneas. Encontro de Ciências Sociais do Norte e Nordeste. Sergipe, Brasil: CIso, Universidade Federal de Sergipe.

Sagarpa [Secretaría de Agricultura, Ganadería, Desarrollo Rural, Pesca y Alimentación]. (2012). Proyecto estratégico para la seguridad alimentaria (PESA). En Línea: http://www.sagarpa.gob.mx/desarrollorural/documents/micrositio\%20pesa/que $\% 20$ es\%20el\%20pesa. pdf

Tortosa, J. M. (2010). Para definir el buen vivir. En Seminario Internacional retos del buen vivir. Democracia, movilidad humana y territorio (pp. 7-20). Cuenca, Ecuador: Pydlos.

Zariñan, M. C. (2011). Estructura económica del municipio de Villa del Carbón, Estado de México (tesis de pregrado ). UAEM, Atizapán, Edomex. 